\title{
VIOLÊNCIA E BULLYING EM CONTEXTO ESCOLAR: CON- TRIBUTOS DA PERSPECTIVA INTERCULTURAL
}

\author{
VIOLENCE AND BULLYING IN SCHOOL CONTEXT: contributions of intercultural \\ perspective
}

\author{
VIOLENCIA Y BULLYING EN EL CONTEXTO ESCOLAR: contribuciones de la per- \\ spectiva intercultural
}

\begin{abstract}
Ana Karina Campos Moreira da Costa Santos Professora Doutora e Investigadora do Centro de Estudos das Migrações e das Relações Interculturais, Universidade Aberta, Lisboa, Portugal. Grupo de Investigação "Saúde, Cultura e Desenvolvimento". anakarinasantos@yahoo.com

Natália Ramos

Diretora do Centro de Estudos das Migrações e das Relações Interculturais. Investigadora Coordenadora do Grupo de Investigação “Saúde, Cultura e Desenvolvimento”, Universidade Aberta, Lisboa. natalia@uab.pt
\end{abstract}

RESUMO: O presente artigo apresenta uma revisão teórica sobre a temática da violência e do bullying em contexto escolar, sustentada na análise alargada de diversas fontes documentais, publicações e literatura científica da especialidade, de vários autores de referência, almejando uma aprofundada compreensão e uma adequada contextualização teórica do fenómeno em estudo. Trata-se da primeira etapa de um trabalho de investigação em desenvolvimento no âmbito da referida problemática, no Centro de Estudos das Migrações e das Relações Interculturais (CEMRI), da Universidade Aberta de Lisboa, Grupo de Investigação "Saúde, Cultura e Desenvolvimento". O trabalho objetiva identificar, analisar e compreender os processos inerentes à construção da violência e da exclusão social em meio escolar português. Pretendemos, também, aferir as principais causas e consequências dos comportamentos violentos em contexto escolar, assim como definir possíveis formas de prevenção e estratégias de intervenção/atuação, nomeadamente através dos contributos da educação intercultural. Para realizar este estudo, ainda em elaboração na sua vertente empírica, optámos pelo método de investigação qualitativa. Escolhemos realizar um estudo de tipo descritivo, na categoria de estudo de caso. Assim, propomo-nos estudar o caso de uma escola do primeiro ciclo do ensino básico, de um agrupamento de escolas do distrito de Setúbal, situada numa zona urbana do concelho do Seixal.

PALAVRAS-CHAVE: Violência. Bullying. Vitimização. Escola. Prevenção. Educação intercultural.

ABSTRACT: This article presents a literature review on the theme of violence and bullying in schools, based on extensive analysis of various documentary sources, publications and scientific literature, from many relevant authors, aiming to achieve a wide understanding and proper contextualization of the phenomenon under study. This is the first stage of a research work that is being developed on the mentioned topic, at the Research Center for Migration and Intercultural Relations (CEMRI), of the Open University of Lisbon, Research Group "Health, Culture and Development". The study aims to identify, analyze and understand the processes involved in the construction of violence and social exclusion in portuguese schools. We also intend to assess the main causes and consequences of violent behavior in schools, as well as finding ways to prevent violence and defining intervention strategies / actions, namely through contributions of intercultural education. To carry out this study, still in progress in its empirical part, we have chosen the qualitative research method. We chose to perform a descriptive study, in the case study category. Therefore, we propose to study the case of a school of the first cycle of basic education (primary school), which belongs to a group of schools from Setúbal district, located in an urban area of Seixal.

KEYWORDS: Violence. Bullying. Victimization. School. Prevention. Intercultural education.

$\overline{\text { Artigo recebido em maio de } 2016}$

Aprovado em julho de 2016 
RESUMEN: En este artículo se presenta una revisión de la literatura sobre el tema de la violencia y la intimidación en las escuelas, en base a un amplio análisis de diversas fuentes documentales, publicaciones e literatura científica, de muchos autores de referencia, con el objetivo de una profunda comprensión y contextualización adecuada del fenómeno en estúdio. Esta es la primera parte de un trabajo de investigación en el desarrollo en el Centro de Estudos en Migración y Relaciones Interculturales (CEMRI), de la Universidad Aberta de Lisboa, Grupo de Investigatión "Salud, Cultura y Desarrollo". El estúdio tiene como objetivoidentificar, analizar y comprender los procesos que intervienen en la construcción de la violencia y la exclusión social en las escuelas portuguesas. Tenemos la intención, también, de identificar las principales causas y consecuencias de los comportamientos violentos en contextos escolar, así como definir posibles formas de prevención y estrategias de intervención/atuación, identificada a través de las contribuciones de la educación intercultural. Para realizar este estudio, todavía en elaboración en su vertiente empírica, optamos por lo método de investigación cualitativa. Elegimos realizar un estudio del tipo descriptivo, en la categoría de estudio de caso. Así, proponemos estudiar el caso de una escuela de primero ciclo de enseñanza básica, de un agrupamiento de esculelas del distrito de Setúrbal, situada en la zona urbana del consejo del Seixal. PALABRAS CLAVE: Violencia. Bullying. Victimización. Escuela. Prevención. Educación intercultural. 


\section{1| INTRODUÇÃO}

A paz não é, não pode ser e nunca será a ausência de conflitos, mas o domínio, a gestão e a resolução dos conflitos por outros meios que não a violência destruidora e assassina. (MULLER, 1995).

A temática da violência em meio escolar tem vindo a assumir uma evidente e crescente relevância nos contextos nacional e internacional, assim como ao nível científico, social e político, posicionando-se com notória importância no âmbito das atuais preocupações que se observam no domínio socioeducativo e da saúde, revelando-se uma problemática impulsionadora de sérios e crescentes desafios que se apresentam às políticas do presente século, implicando um exercício de reflexão fundamentada e problematizadora. Dado o caráter universal da problemática do bullying em contexto escolar, impõe-se uma consistente consciência coletiva de (re)pensar as realidades educativas, sociais e políticas, apelando para olhares críticos, abordagens ativas e intervenções contextualizadas, que possibilitem explorar e desenvolver percursos que ajudem a resolver os problemas identificados e as dificuldades constatadas e responder, eficazmente, às inúmeras questões que se traduzem em múltiplas inquietações, vivenciadas diariamente, em diversas situações e contextos nos quais atuamos.

No mundo contemporâneo e globalizado, considerando a importância atribuída às questões da violência, dos estereótipos e perconceitos, da segregação social e cultural, das desigualdades e da exclusão social como fenómenos verdadeiramente preocupantes, resultantes de fatores sociais, culturais e do visível aumento das desigualdades sociais e dos conflitos interpessoais e interculturais, é possível constatarmos um interesse renovado e um aumento relativamente à complexa, abrangente e plurifacetada temática da violência, que tem vindo a destacar-se como tema com projeção mediática e como um importante objeto de estudo interdisciplinar em todo o mundo, sobretudo a partir das duas últimas décadas do século XX e inícios do século XXI, atingindo todas as gerações, sexos e contextos, nomeadamente as crianças e jovens e o contexto escolar. Com efeito, a violência está presente na vida das crianças e dos jovens em todo o mundo, independentemente de fatores como etnia, religião, cultura, sexo, estatuto económico e social, e sempre com consequências imediatas, ou a médio e a longo prazo (RAMOS, 2004, 2013a; UNICEF, 2014).

O Relatório das Nações Unidas para a Infância Hidden in plain sight (UNICEF, 2014), num estudo a nível mundial abrangendo 190 países, incluindo Portugal, revela que mais de um em cada três alunos, com idades compreendidas entre os 13 e os 15 anos, passam regularmente por, pelo menos, uma experiência de bullying.

A Organização Mundial de Saúde (OMS) considera que a violência exercida contra as crianças e adolescentes representa, indiscutivelmente, um grave problema de saúde pública e um sério motivo de preocupação, não somente ao nível da prevenção, mas, também, ao nível do acompanhamento das vítimas e testemunhas, nomeadamente no que se refere ao acompanhamento pós-traumático dirigido às mesmas (RAMOS, 2004; BLAYA, 2008).

Blaya (2008) reforça que vivenciar situações de violência, designadamente em meio escolar, seja no papel de vítima, agressor, vítima/agressor ou testemunha, poderá originar distúrbios diversos, especificamente, problemas de inserção social ou problemas de saúde mental, situando assim a problemática da violência em contexto escolar como um objeto de profunda preocupação e complexidade, esclarecendo, ainda, para a necessidade de implementar medidas e dinamizar programas que visem a redução da violência nas comunidades escolares e assegurem a prevenção de problemas psicossociais das crianças e dos adolescentes.

Sabemos que a violência é um fenómeno de causas múltiplas, socialmente construído, e que a sua perceção é construída individualmente (pelo agressor, pela vítima ou testemunha) ou 
coletivamente (através dos meios de comunicação e da cultura da sociedade na qual nos encontramos inseridos), e varia de acordo com os contextos, as culturas e as épocas (CHESNAIS, 1981). Na abordagem socioconstrutivista, a violência decorre da interação entre indivíduos, das interpretações das suas ações, bem como das decisões daí resultantes, em determinado contexto cultural, político e ideológico, de acordo com os interesses e de uma posição social que lhes são próprios num dado momento (BLAYA, 2008).

Devemos, assim, procurar compreender o fenómeno de forma holística e aprofundar conhecimentos sobre esta problemática multivariável, adquirindo uma maior conciência acerca da violência e das suas diferentes formas de manifestação, para então melhor atuar e intervir em múltiplas situações e diversos contextos onde esta se manifeste, bem como encontrar e operacionalizar estratégias e medidas eficazes que possam contribuir para uma adequada abordagem ao fenómeno, uma intervenção multi/interdisciplinar em situações de violência e o desenvolvimento de mecanismos que sustentem a sua prevenção, nomeadamente, em meio escolar.

A escola representa um vasto sistema, complexo e dinâmico, integrado num conjunto de múltiplas estruturas económicas e sociopolíticas que configuram a sociedade e que nela produzem amplas conexões e dependências entre as suas quatro grandes esferas de atividade e atuação, designadamente: o microssistema (a sala de aula, cenário concreto onde se realizam e desenvolvem os processos de ensino e aprendizagem); o mesossistema (a instituição escolar e o respectivo projeto curricular); o exossistema (a administração educativa) e o macrossistema (o sistema envolvente, a sociedade, os valores e a cultura global) (PESCADOR; DOMíNGUEZ, 2001).

Importa compreender que:

A violência, presente nos quatro níveis acima referidos, exigirá uma abordagem diferente da habitual e que se caracterize pelo facto de ser sistémica e ecológicocomunicativa, interdisciplinar e integral, ou seja, uma abordagem que contemple o todo do ser humano, que se ocupe dos conhecimentos, sentimentos, valores e atitudes, dos aspectos físicos e psíquicos, do afectivo e do racional; que cultive a liberdade de ideias, a razão, o pensamento crítico, os valores democráticos, a solidariedade, a justiça social, a resolução não-violenta dos conflitos, a aceitação da diversidade (cultural, étnica, religiosa, sexual...), um modelo pedagógico para uma escola que vise a inclusão e não a exclusão. (PEDRO et al., 2012, p. 16).

Pedro et al. (2012) sublinham que os cursos de formação inicial de professores deverão englobar um módulo ou programas que abordem a compreensão e a prevenção de problemas de violência e comportamento agressivo em contexto escolar, com ênfase no recurso à gestão democrática e à educação pela paz e para a paz, permitindo, assim, conceber a escola como um verdadeiro espaço de cultura e de vivência democrática, que promove o trabalho colaborativo, o encontro de culturas e a troca de experiências, a partilha do conhecimento e da cultura, o reconhecimento da complexidade e da heterogeneidade humana e social, o respeito pelas diferenças individuais e o diálogo intercultural.

Tomando em consideração que a problemática da violência constitui apenas uma das muitas dimensões da vida da instituição escolar, não será certamente difícil perceber que a violência influencie e seja influenciada por outras dimensões. Assim, no decurso da resolução do problema devem considerar-se todos os intervenientes, ou seja, as vítimas, os agressores, os espectadores de violência ou testemunhas, mas, também, o clima da escola, a família e a sociedade (VEIGA, 2001; PEDRO et al., 2012).

A violência em contexto escolar, sendo caraterizada por vários autores como um fenómeno abrangente, complexo, multifacetado e multidimensional, que merece a atenção de profissionais de 
diferentes áreas, poderá assumir uma multiplicidade de manifestações, nomeadamente, distúrbios de comportamento, comportamentos de oposição, violência física e verbal, perturbação da atenção com hiperatividade, vandalismo, comportamento delinquente, déficit de competências, fatores desenvolvimentais ou bullying, reclamando uma abordagem holística e multidisciplinar (COSTA, 2001).

Relativamente à delinquência juvenil e atendendo a vários trabalhos de investigação realizados neste âmbito, podemos concluir que a idade considerada crítica, em qualquer país, situa-se entre os 14 e os 18 anos (JUNGER-TAS; MARSHALL; RIBEAUD, 2003; ROCHÉ, 2003).

Importa referir que a comunidade internacional de investigadores que estudam e divulgam este complexo e emergente fenómeno, nem sempre reúne consenso sobre a definição de violência em meio escolar, nem mesmo sobre os comportamentos abrangidos. Assim, cabe considerar e reconhecer as evidentes dificuldades existentes na produção de conhecimento consensual sobre a temática da violência nas escolas, e a necessidade do alargamento dos estudos na área, dada a divergência de opiniões e posições constatada entre os inúmeros estudiosos e investigadores.

A escola não configura uma posição inócua ou neutra na produção de contextos e situações violentas. Como refere Ramos (2004, p. 70) " a escola, espaço de desenvolvimento e relacional por excelência, tornou-se também espaço de múltiplas formas de violência”, onde múltiplas variáveis pessoais, familiares, culturais e escolares contribuem para diversas formas de violência, nomeadamente o bullying. Assim, relativamente aos fatores de risco escolar que favorecem a violência, importa compreender que o meio escolar poderá criar, fazer emergir, cristalizar ou até mesmo agravar consideravelmente os conflitos, desencadeando comportamentos violentos. Todavia, posicionando-se como lugar essencial e privilegiado de socialização, a instituição escolar também poderá assumir um papel fundamental na prevenção e no combate à violência e à delinquência, sendo que a violência em meio escolar encontra-se, inúmeras vezes, associada à delinquência dos menores, porém, poderá também traduzir-se na vitimização dos mesmos (BLAYA, 2008).

Ora, a educação intercultural, sustentando-se no efetivo reconhecimento dos direitos humanos, do direito à diferença e do respeito pelas diferenças individuais, põe em evidência a singularidade e a diversidade, fazendo ressaltar a emergência do respeito pelas pessoas e pelas culturas e acentuando a importância do universalismo diferenciado. Como tal, através da educação e da pedagogia intercultural, a escola poderá abrir caminho para uma convivialidade saudável e melhorar o seu clima social, reforçando o ensino/aprendizagem de competências e habilidades no âmbito da solidariedade e da cooperação, da tolerância, do respeito pelos outros, da dignidade humana, da união e entreajuda, da resolução de problemas e conflitos sem violência, da disponibilidade permanente para ajudar os outros, da empatia, do altruísmo e do enriquecimento mútuo entre pessoas de diferentes culturas. Este caminho irá, certamente, contribuir para prevenir e combater comportamentos agressivos e violentos, ajudar a educar para a não violência, fortalecer relações positivas entre as crianças e jovens de diferentes culturas que convivem nas comunidades educativas e reduzir as limitações pessoais e culturais existentes na comunicação e na compreensão do mundo multi/ intercultural contemporâneo, preparando os indivíduos para o exercício consciente e pleno da cidadania. (PERES, 2000; RAMOS, 2007a, 2007b, 2008, 2011, 2013a, 2013b; PEDRO et al., 2012).

Os vários estudos internacionais sobre school bullying permitem concluir que existe uma percentagem que varia entre os $5 \%$ e os $12 \%$ de alunos vítimas no primeiro ciclo do ensino básico, sendo a percentagem em Itália (17,5\%) e em Portugal (21,9\%) bastante mais elevada. Em Portugal, a violência observada nas instituições escolares traduz, como comportamentos mais frequentes, a luta e as agressões físicas (COWIE; SMITH, 2001; HAYDEN; BLAYA, 2001; BLAYA, 2008).

Investigadores e especialistas em todo o mundo dirigem um olhar atento para este fenómeno, que assume contornos notoriamente preocupantes relativamente ao seu crescimento e, especialmente, 
por implicar crianças que frequentam os primeiros anos de escolaridade. Assim, estima-se que cerca de $5 \%$ a $35 \%$ das crianças em idade escolar encontram-se envolvidas em episódios de agressividade e de violência nas instituições escolares que frequentam (FANTE, 2002).

Em referência a resultados mais atuais sobre a incidência de adolescentes que foram vítimas, recentemente, de bullying a nível mundial, o Relatório das Nações Unidas para a Infância Hidden in plain sight (UNICEF, 2014) destaca que as taxas vão desde $7 \%$ no Tajiquistão a $74 \%$ em Samoa. Perto de $31 \%$ dos adolescentes na Europa e na América do Norte admitem praticar bullying contra os seus pares, com uma taxa de prevalência que vai de cerca de $14 \%$ na República Checa e na Suécia, a cerca de 59\% na Letónia e na Roménia, existindo uma predominância dos rapazes em relação às meninas. Segundo, ainda, este relatório (UNICEF, 2014), a média nacional de adolescentes que praticam bullying em Portugal encontra-se 6\% acima da europeia. A Unicef revela que $37 \%$ dos adolescentes portugueses dizem ter praticado bullying nos últimos seis meses. Este número encontra-se acima da média europeia e norte-americana, que se situa nos $31 \%$.

De acordo com Sá (2012), a problemática da violência e do bullying nas escolas, em Portugal, não sendo claramente um fenómeno novo, tem vindo a revelar uma visibilidade crescente, decorrente de vários fatores, nomeadamente, o aumento no número de incidentes reportados envolvendo alunos, professores e assistentes operacionais e/ou, ainda, como resultado da maior atenção atribuída ao(s) fenómeno(s) pelos meios de comunicação social (os media). Aliás, Estrela e Marmoz (2006) reforçam que a violência e a indisciplina em contexto escolar assumiram uma presença mais sistemática e até constrangedora, numa sociedade em crescente crise de valores e permanentemente confrontada com profundos e diversos desequilíbrios, constituindo uma fonte de inquietação para os pais, as famílias, os educadores/professores, os assistentes operacionais, os diretores das instituições escolares, os investigadores, os profissionais de saúde, a sociedade civil, a opinião pública, e, também, para os decisores políticos.

A partir dos anos 80, têm vindo a ser implementados de forma crescente e a nível internacional, vários programas de intervenção, destacando-se o importantíssimo e pioneiro contributo do norueguês Dan Olweus (SÁ, 2012).

\section{2 | GÉNESE E DESENVOLVIMENTO DOS ESTUDOS DO BULLYING}

Através da revisão da literatura existente sobre a temática do bullying, constatamos que o estudo sistemático desta problemática interdisciplinar teve início na década de 70 do século XX, materializando-se através do inestimável contributo dos investigadores Paul Heinemann e Dan Olweus.

A problemática do bullying adquiriu notória visibilidade com a publicação do livro de Heinemann intitulado Mobbning - Gruppvåld bland barn och vuxna, bem como com a divulgação dos resultados obtidos através de inúmeras observações diretas realizadas nos contextos dos recreios de várias instituições escolares na Suécia (FORMOSINHO; SIMÕES, 2001; PEREIRA et al., 2004).

Também Olweus vem contribuir, incontornavelmente, para a divulgação deste fenómeno, com a publicação, em 1973, do livro Hackkycklingar och översittare, através do qual divulga os resultados do primeiro estudo empírico sobre bullying realizado no mundo, tendo aferido, entre outras importantes conclusões, que cerca de $10 \%$ da população escolar norueguesa se envolvia em episódios de bullying. O estudo de Olweus constitui um marco incontestável no âmbito da investigação produzida sobre a temática do bullying, destacando-se pela sua profundidade, complexidade e dimensão. Seguidos alguns anos desta primeira publicação, foi editada em língua inglesa, em 1978, nos Estados Unidos da América, uma edição atualizada e ampliada do primeiro estudo de Olweus, com o título "Aggression in the Schools: Bullies and Whipping Boys" (RAMIREZ, 2001). 
Na obra intitulada "Bullying at School: what we know and what we can do" Olweus (2005) destaca que o bullying entre crianças, nas escolas, é um fenómeno frequente e bastante antigo, esclarecendo, assim, que o bullying não é uma problemática circunscrita à atualidade, apenas assumiu maior visibilidade, despertando a crescente e pertinente atenção da sociedade em geral, da comunidade científica, mas, em particular, dos psicólogos, pedopsicólogos clínicos, psicanalistas, psicoterapeutas e pediatras, conscientes das consequências e do perigo que representa ignorar, revelar indiferença, minimizar, tolerar ou até negar este grave problema, vivenciado por crianças, jovens e, também, por adultos, em todo o mundo.

Em relação ao fenómeno bullying e à compreensão dos seus contextos e das suas dinâmicas, a década de 90 do século XX, destacou-se, efetivamente, como um período de crescente interesse e considerável preocupação (OLWEUS, 1999). Em Portugal, as investigações efetuadas sobre a temática têm vindo a ser realizadas desde meados dos anos 90 (VEIGA, 2001; CARVALHOSA; MOLEIRO; SALES, 2009a, 2009b), observando-se um maior volume de estudos a partir de 2006.

O crescente interesse pelo tema entre a comunidade científica, impulsionando vários estudos científicos desenvolvidos por especialistas e investigadores, bem como a ampla divulgação do fenómeno, nomeadamente pelos diferentes órgãos de comunicação social, tem alertado para a urgência de uma melhor compreensão e maior consciencialização da sociedade, face à problemática do bullying que, devido à sua extrema complexidade e evidente multidimencionalidade, requer uma séria e cuidada abordagem.

O bullying é uma problemática mundial e nenhuma sociedade pode ficar indiferente ao sofrimento vivido e, tantas vezes silenciado, por medo e vergonha, pelas vítimas deste grave problema que poderá transformar a vida dos nossos filhos, netos, irmãos, primos, sobrinhos, amigos, alunos, num verdadeiro pesadelo, muitas vezes, sem fim à vista. Todos temos a responsabilidade e o dever consciente de procurar compreender e não ignorar para, então, melhor atuar, de modo a prevenir e combater, eficazmente, a violência e os comportamentos de bullying observados e vivenciados em diversas situações e contextos.

\section{3 | DEFINIÇÃO DE BULLYING}

O termo bullying, que se reporta a um tipo específico de violência escolar, apareceu com os estudos de Olweus e seus colaboradores, em 1973 (OLWEUS, 1978, 1993, 2005), referindo-se a qualquer comportamento que evidenciasse agressão entre crianças, em que um ou vários indivíduos abusa de forma intencional da sua posição de superioridade em relação à vítima, com o objetivo de lhe causar mal, repetidamente, ao longo do tempo, observando-se claramente uma relação desigual de poder e força (FERREIRA; PEREIRA, 2001; RAMIREZ, 2001; MARTÍNEZ, 2002; PEREIRA, 2008).

Olweus (1998, p. 34) define bullying como "uma conduta de perseguição física e/ou psicológica, de um aluno sobre outro, eleito como vítima de repetidos ataques".

Na opinião de Costa e Vale (1998), o bullying não se encontra limitado à agressividade física, podendo ser considerados vários comportamentos agressivos, violentos e negativos, tal como chamar nomes ofensivos e humilhantes ou atribuir alcunhas cruéis; dizer coisas desagradáveis, incómodas ou constrangedoras acerca de determinada pessoa; espalhar rumores ou enviar recados insultuosos, intimidativos ou ameaçadores, provocando medo, temor e sofrimento na vítima; difamar; perseguir, assediar e aterrorizar de forma sistemática e persistente; ignorar, excluir ou isolar socialmente; agredir fisicamente; violentar sexualmente ou mesmo roubar, danificar ou destruir bens pessoais de outrem. 
Segundo Lopes Neto e Saavedra (2003) devem ser consideradas bullying todas as atitudes que expressem agressividade, infligidas de forma intencional e repetida, sem motivação evidente, assumidas por um ou mais alunos contra outro(s), com o objetivo claro de causar angústia e dor, sempre protagonizadas numa relação desigual de força e poder, tornando assim possível intimidar a(s) vítima(s).

A identificação de comportamentos de bullying comporta uma evidente multiplicidade de construções conceptuais e poderá não representar um processo fácil. Assim, Pereira (2008) lembra que para podermos identificar um comportamento como bullying torna-se necessário observar a presença de três fatores fundamentais. Como tal, o mal infligido ao outro não resulta de uma eventual provocação, assumindo antes um caráter deliberado. Assim, a vitimação e as intimidações não ocorrem de forma ocasional, ou seja, existe uma clara intenção em causar mal e medo, provocar sofrimento ou infligir dor emocional ou física à vítima. Por fim, os agressores são, em geral, fisicamente mais fortes e possuem um perfil ameaçador e notoriamente violento, observando-se uma evidente desproporcionalidade de poder, dificultando desta forma que a vítima possa defender-se ou pedir auxílio/ajuda.

Importa destacar que o fenómeno do bullying reveste-se de uma enorme complexidade, que se estende à dificuldade de consenso entre investigadores, relativamente à sua definição, nomeadamente devido à multiplicidade de comportamentos identificados e considerados, ou não, pelos diferentes autores, o que dificulta a existência de unanimidade e cria algumas dificuldades face à adoção de uma definição universalmente aceite.

\section{4| EFEITOS E CONSEQUÊNCIAS DO BULLYING}

Os estudos desenvolvidos em diversos países por investigadores e especialistas do fenómeno bullying confirmam e reforçam que a violência nas escolas apresenta sérias consequências para as vítimas, para os agressores, para as testemunhas, para o grupo de pares e restantes alunos que frequentam a instituição escolar, mas, também, para a escola, nomeadamente no que se refere à degradação do ambiente escolar, bem como para a comunidade envolvente. As inúmeras repercussões decorrentes desta problemática poderão observar-se a curto, médio e longo prazo, na vida das pessoas que se encontram direta ou indiretamente envolvidas e nos vários contextos onde ocorre.

Singer et al. (1995) sublinham que a exposição à violência imprime sequelas preocupantes e acarreta graves implicações ao nível das capacidades de socialização dos indivíduos, que se traduzem, com frequência, em distúrbios da socialização, observando-se claramente uma diminuição das competências sociais nos indivíduos identificados como vítimas de violência. Também Olweus (1978) aborda os distúrbios da socialização decorrentes da vitimização, relembrando que uma parte significativa das crianças e adolescentes vítimas de violência regular assumem, muitas vezes, o papel de agressores.

Assim, a violência nos estabelecimentos escolares constitui um grave e preocupante problema que poderá afetar e colocar em risco o bem-estar, a saúde física e mental, e a capacidade de progressão das crianças e adolescentes a nível social, mas, também, académico. Inúmeras investigações aferiram que as vítimas de bullying revelam tendência para o isolamento, ideias de suicídio, baixa autoestima e insegurança, atormentadas com o receio de represálias ou por se sentirem inferiores e, por vezes, sentem vergonha ou desenvolvem um sentimento de culpa por se deixarem vitimizar, consumindo-se num preocupante e constante sofrimento psíquico. Este tipo de vítimas regista, ainda, taxas elevadas de queixas somáticas e sintomas de doenças físicas, bem como problemas de sono e alimentares (FERREIRA; PEREIRA, 2001; RAMOS, 2004; BEANE, 2006, 2011; PAIAS; ALMEIDA, 2006). 
Os seus efeitos não se limitam apenas ao período escolar, podendo ter consequências graves e, muitas vezes, irreversíveis, na vida futura das vítimas de violência e bullying, em especial para aqueles que, tendo sido vitimados durante um período de tempo considerável, poderão não conseguir superar os traumas vivenciados na escola, tornando-se adultos com sérios problemas depressivos, de relacionamento e baixa autoestima, ou, ainda, assumindo comportamentos agressivos e violentos em casa (violência doméstica) e/ou no local de trabalho. Crianças violentadas têm maior propensão para a violência e depressão. Com efeito, são bastante frequentes as depressões e o aparecimento de fobias ou doenças psicossomáticas. Em casos mais extremos e, quando não procuram ou recebem ajuda especializada atempada, poderão tentar o suicídio ou mesmo cometer suicídio (LOPES NETO; MONTEIRO FILHO; SAAVEDRA, 2003; RAMOS, 2004; SMITH et al., 2004; SMITH; PEPLER; RIGBY, 2004).

Estudos nacionais e internacionais realizados por investigadores e estudiosos alertam-nos, claramente, para o facto de que os alunos que assumiram comportamentos de bullying nas escolas poderão adotar, na vida adulta, comportamentos agressivos, violentos e antissociais, no seio familiar, no local de trabalho ou em diferentes situações e contextos sociais, ou, até mesmo, envolverem-se em atos de vandalismo, delinquência ou ações criminosas (LOPES NETO; MONTEIRO FILHO; SAAVEDRA, 2003; RAMOS, 2004).

Relativamente às testemunhas de comportamentos de bullying, os estudos indicam que estas também são, geralmente, afetadas emocionalmente e psicossocialmente, por terem testemunhado atos de agressão e violência e presenciado ambientes de grande tensão e conflito, podendo tornar-se pessoas inseguras e com medo de poderem vir a ser a próxima vítima de temíveis agressores. Podem, também, desenvolver episódios de ansiedade ou incorrer em situações de angústia e baixa autoestima, por se sentirem incapazes de ajudar o(s) colega(s)/amigo(s) em situação de dificuldade ou perigo ou, ainda, tornarem-se insensíveis ou alheios à dor e ao sofrimentos dos outros, aceitando a agressão e a violência como um meio para alcançar determinado objetivo (LOPES NETO; MONTEIRO FILHO; SAAVEDRA, 2003).

Por conseguinte, urge esclarecer adequadamente e sensibilizar toda a comunidade educativa e a sociedade em geral, no sentido de apoiar e proteger as vítimas de práticas agressivas e comportamentos de bullying, para que estas se sintam seguras e consigam, então, denunciar o(s) agressor(es) e descrever a violência à qual têm sido sujeitas, permitindo à escola agir precocemente, de forma a combater e fazer cessar a violência identificada, eliminando a dinâmica de bullying e libertando as vítimas de um doloroso ciclo de sofrimento, através da efetiva e ativa compreensão, colaboração e disponibilidade de todos.

\section{5| EDUCAÇÃO INTERCULTURAL NA PREVENÇÃO DA VIOLÊNCIA}

É necessário assumir a diversidade e a multipertença como uma riqueza. A educação para a pluralidade é não só uma proteção contra a violência, mas, também, um princípio ativo de enriquecimento cultural e cívico das sociedades contemporâneas. (DELORS et al., 1996).

Segundo vários estudiosos e investigadores como Olweus (1993, 2005), Smith e Sharp (1994), Mellor (1997), Smith (1999), Veiga (2001), Thompson, Arora e Sharp (2003), Ramos (2004) e Pereira (2008), a prevenção da violência e do bullying nas escolas requer a definição rigorosa de estratégias e a aplicação cuidada e devidamente monitorizada de medidas de intervenção e prevenção contextualizadas e adequadas à realidade institucional. Implica igualmente um envolvimento e comprometimento de toda a comunidade educativa, devidamente informada/esclarecida e munida das ferramentas e competências necessárias, implicando assim alunos, educadores/ 
professores, assistentes operacionais, psicólogos, terapeutas e demais agentes educativos, bem como pais e encarregados de educação, famílias e outros elementos da comunidade envolvente, ou seja, uma intervenção multidisciplinar, consistente e sistemática, sustentada por políticas públicas locais e globais, capazes de combater com sucesso este complexo e abrangente fenómeno. $\mathrm{E}$, quando bem definidas e aplicadas, as medidas implementadas pela instituição escolar para prevenir e combater os comportamentos de bullying ou outras formas de violência, terão, certamente, maior probabilidade de alcançar resultados positivos e contribuir para um ambiente escolar mais seguro, motivador de aprendizagem e orientado para a não violência, onde todos se possam sentir verdadeiramente felizes, confiantes, aceites e respeitados.

Cabe sublinhar que qualquer manifestação de indisciplina ou violência, mesmo quando não seja caracterizada como grave ou muito grave, nunca deverá ser ignorada ou desvalorizada, exigindo, sempre, um olhar atento e a implementação imediata de medidas que visem controlar atempadamente as situações observadas/diagnosticadas nas comunidades educativas, evitando e prevenindo, assim, que estas possam continuar, avolumar-se e evoluir para situações mais graves de violência ou mesmo de bullying, dificultando a intervenção eficaz junto dos envolvidos, quer sejam vítimas, agressores ou testemunhas.

$\mathrm{Na}$ literatura científica da especialidade, vários investigadores e estudiosos/especialistas alertam para a necessidade e urgência de programas de prevenção, intervenção e combate à violência nas escolas, destacando que as especificidades das realidades escolares requerem programas devidamente contextualizados, que possam efetivamente responder aos problemas diagnosticados, sendo que o sucesso de um programa impõe que cada comunidade escolar proceda à definição rigorosa de estratégias, medidas e intervenções específicas, dirrecionadas às necessidades e características observadas e de acordo com os objetivos que se pretendem alcançar (VEIGA, 2001; RAMOS, 2004).

Recordemos, porém, que a instituição escolar é geradora de comportamentos, situações e contextos violentos quando, sem refletir profundamente acerca das consequências e nocividade das atitudes e decisões, muitas vezes assumidas, nomeadamente por lacunas e fragilidades na formação e nas competências dos profissionais, não considera as diferenças e as identidades culturais, étnicas, religiosas, sexuais, geracionais; não respeita as diversidades linguísticas e comunicacionais, os diferentes modos de vida, os projetos individuais e as singularidades dos alunos; não respeita as diferenças afetivas, emocionais, sociais e cognitivas; não ajuda os alunos a aceitar e a lidar com as diferenças, não combate os preconceitos, os estereótipos, as atitudes discriminatórias e a marginalização; não promove a alteridade e a diferença. Mas, também, quando apresenta um currículo comum/padrão, rígido e monocultural, e, assim, limita o acesso ao currículo dos alunos pertencentes a minorias e a grupos socialmente desfavorecidos e não combate as desigualdades educativas, sociais, culturais e de género (PERES, 2000; GONZÁLEZ, 2002; RAMOS, 2007a, 2007b, 2008, 2011, 2013a, 2013b; SANTOS, 2012).

Como sublinha Ramos (2013a, p. 129):

A educação e formação inicial, ou continuada dos profissionais, deverão constituir um locus cultural e educativo privilegiado para a discussão e aprendizagem multi/intercultural. Deverão contribuir para a reflexão e implementação de atitudes e práticas que possibilitem novas estratégias e competências face à diversidade individual e cultural e desenvolver a consciência cultural para a prevenção de estereótipos e preconceitos étnicos, culturais, intergeracionais, religiosos, sexuais, de género, (muitas vezes na origem da violência), tendo em vista o desempenho positivo e o acolhimento de jovens pertencentes aos vários universos culturais. 
Acreditamos que a educação intercultural e o currículo intercultural poderão contribuir de forma bastante positiva na prevenção e no combate à violência gerada na escola e pela escola, ajudando a melhorar a qualidade do ensino e das aprendizagens e as capacidades dos professores para atuar face à diversidade e melhor compreender o mundo global e culturalmente plural no qual vivemos. Poderá, ainda, fomentar a construção e a promoção de uma cultura de tolerância e paz, para que todas as crianças e jovens possam, então, estudar numa escola segura e solidária e viver num mundo com cidadãos conscientes face à imperatividade do respeito pela pessoa na sua singularidade e diferença; uma escola inclusiva, emancipadora e liberta de preconceitos, que assume inteiramente a responsabilidade do seu importante papel socializador, visando contribuir para a formação de cidadãos íntegros e civicamente responsáveis, capazes de fazer emergir e imprimir mudanças efetivas na escola e na sociedade e ajudar a construir um mundo mais justo e verdadeiramente solidário.

Santos (2012) reforça que a escola inclusiva e intercultural, consciente da diversidade discente, deverá reconhecer e respeitar a individualidade e a singularidade dos seus alunos, educar para os valores, para a participação ativa, para a cidadania e para a tolerância, assegurando contextos de aprendizagem acolhedores, estimulantes, enriquecedores, saudáveis e seguros, orientados para a não violência e para a efetiva inclusão de todas as crianças e jovens, protegendo, assim, o seu equilíbrio emocional e bem-estar, favorecendo a realização pessoal e social e garantindo percursos em direção ao êxito e ao efetivo sucesso educativo.

Ressalte-se, então, que os programas de intervenção e combate à violência nas comunidades escolares deverão contemplar na sua estrutura, incontornavelmente, a vertente intercultural, salvaguardando e dando relevo à educação intercultural e à pedagogia intercultural na prevenção e no combate às desigualdades educativas e à violência, impulsionando a análise e a eliminação eficaz de situações e realidades escolares que possam produzir desigualdades, através da conceção e implementação de projetos educativos e sociais que favoreçam e façam sobressair os caminhos para a efetiva inclusão de todas as crianças e jovens nas nossas escolas e nas comunidades, pois, como refere e sublinha Allmen (1994), importa repensar, seriamente, o intercultural na sala de aula, na escola e na comunidade.

A instituição escolar deverá promover e reforçar a educação de valores éticos, a educação cívica e garantir aos seus alunos a oportunidade de aprender e compreender a importância da justiça, da solidariedade, da entreajuda, da lealdade, da honestidade, da humildade, do afeto e da preocupação pelos outros, assegurando e consolidando, assim, a formação moral e ética dos alunos, o seu desenvolvimento afetivo e relacional e a maximização de competências pessoais, sociais e cívicas.

A escola, enquanto espaço privilegiado de aprendizagem e de formação pessoal e social, mas, também, enquanto lugar de convivência, cooperação e resolução partilhada de conflitos, deverá investir na edificação de projetos educativos e curriculares orientados para a diversidade discente presente nas comunidades educativas, que facilitem a efetiva inclusão de todos os alunos, sem exceções e, particularmente, dos alunos pertencentes a grupos minoritários, salvaguardando a criação de estruturas pedagógicas que possibilitem a implementação e a promoção dos valores de tolerância, equidade e respeito pelas diferenças individuais, protegendo e garantindo a dignidade e a identidade pessoal e cultural de todas as crianças e jovens que frequentam a instituição escolar, afirmando-se como espaço de dinamismo cultural, de desenvolvimento e de aprendizagem.

Aliás, Nogueira $(2005,2007)$ afirma que a escola não tem conseguido desempenhar a sua importante missão enquanto instituição transmissora de valores sociais, permitindo que o espaço escolar seja invadido por atitudes discriminatórias e xenófobas, por ações desencadeadas por preconceitos e estereótipos, por manifestações de intolerância e incivilidades, chamando ainda a 
a atenção para as dificuldades que as instituições escolares têm vindo a revelar na gestão de contextos de violências, o que reforça a ideia de que as comunidade escolares não se encontram, ainda, devidamente preparadas para atuar e intervir, eficazmente, em situações de ocorrência de comportamentos de violência ou bullying.

Ramos (2007a, 2007b, 2008, 2011, 2013a, 2013b) relembra que as comunidades escolares deverão desenvolver espaços de acolhimento promotores de escuta, empatia, flexibilidade, abertura, alteridade, criatividade, cidadania e solidariedade entre alunos e entre professores/educadores; deverão incrementar a formação dos profissionais, desenvolvendo e reforçando competências pedagógicas, relacionais, comunicacionais e (inter)culturais; deverão, ainda, fomentar o respeito pela diversidade e singularidade e o fortalecimento de relações interpessoais e sociais harmoniosas e saudáveis, contribuindo, assim, para a eliminação de desigualdades educativas e sociais e para o permanente reforço da inclusão, do desenvolvimento, da equidade e da justiça social.

\section{6| CONSIDERAÇÕES FINAIS}

A violência nas escolas assumiu uma dimensão nacional e mundial que não poderá ser ignorada ou negligenciada, ocupando um lugar de destaque no âmbito das preocupações observadas no domínio social, educativo, político e da saúde pública, bem como de organismos internacionais como a OMS e a UNICEF. Tratando-se de um fenómeno pluridimensional, de grande complexidade, muitas são as questões, dúvidas e interrogações que se colocam na abordagem à temática, amplamente explorada e estudada por inúmeros investigadores e especialistas, procurando-se, assim, compreender aprofundadamente e holisticamente o fenómeno, de forma a encontrar respostas, soluções e medidas eficazes, orientadas para a diminuição/resolução dos problemas advindos, que contaminam e prejudicam o clima escolar das comunidades educativas onde estudam, diariamente, as nossas crianças e jovens.

A literatura da especialidade esclarece e explica que a violência que ocorre nas comunidades educativas, com crianças em idade escolar, constitui um fator de risco para a saúde física e mental, mas, também, afeta negativamente o desenvolvimento equilibrado e saudável das crianças e jovens, acarretando graves problemas no âmbito da autoestima, da autoconfiança, da autoperceção, da socialização e dos processos de aprendizagem.

De forma a garantir uma gestão adequada e contextualizada dos conflitos observados entre os alunos, assim como, prevenir e combater a violência e o bullying em contexto escolar, torna-se fundamental, antes de mais, harmonizar atitudes e estilos de comunicação, desenvolver e assegurar pontes de diálogo, criar plataformas de compreensão e promover um trabalho colaborativo, coerente e sistemático, bem como um envolvimento ativo e permanente entre todos os elementos da comunidade educativa, assegurando o desenvolvimento de uma pedagogia de diálogo aberto e de mediação face à violência.

Nos estudos realizados em Portugal por Ferreira (2008) e Sá (2012), no âmbito da gestão e prevenção da violência em contexto escolar, os investigadores concluem e salientam que, independentemente das causas e dos responsáveis pelos comportamentos disruptivos manifestados pelos alunos nas escolas, observa-se fundamental uma efetiva articulação e uma sistemática cooperação entre os responsáveis das comunidades educativas (pais e famílias, professores, assistentes operacionais, direção dos estabelecimentos de ensino e demais agentes educativos) e da sociedade em geral, de forma a refletirem e discutirem amplamente esta problemática coletiva, sem preconceitos ou fronteiras, almejando encontrar estratégias capazes de ajudar os alunos a gerir os seus conflitos de um modo positivo, prevenindo, atempadamente, que estes possam evoluir para situações de violência ou bullying. 
Vários autores têm destacado que a formação inicial e contínua de professores no âmbito da violência e comportamentos de bullying em contexto escolar é fundamental e necessária, porém, mencionam que não se observa suficiente, pois, perante a complexidade, a expansão e a universalidade do fenómeno, impõem-se uma atuação multidisciplinar e uma política global, que envolva a escola, as famílias, toda a comunidade, mas, também, a sociedade em geral, de forma concertada e coesa, para uma ação partilhada, realmente eficiente e bem sucedida (MELLOR, 1997; THOMPSON; ARORA; SHARP, 2003).

Quando concebidos atendendo aos contextos específicos de cada instituição escolar, os programas e projetos de intervenção e combate à violência e ao bullying poderão revelar-se verdadeiramente eficazes e ajudar a resolver situações devidamente diagnosticadas, assim como, contribuir para prevenir o desenvolvimento de comportamentos disruptivos, violentos ou de bullying. Contudo, na opinião de vários especialistas nesta matéria, nenhum programa deverá ser concebido e implementado sem um diagnóstico prévio da realidade escolar, aprofundado e rigoroso, que permita conhecer as suas dinâmicas, as características específicas, as particularidades, os problemas, as carências, as dificuldades e o contexto onde se encontra inserida (YOON; KERBER, 2003; OLWEUS, 2005).

Salientemos, igualmente, o importante e indispensável papel da sensibilização, da informação e da formação, para uma adequada compreensão e gestão deste fenómeno, assim como para o desenvolvimento de uma consciência e responsabilidade crítica e informada, capaz de impulsionar uma renovação das representações e dos comportamentos, e combater os diversos mitos e preconceitos existentes relativamente às questões da violência e do bullying entre crianças em idade escolar, promovendo a intervenção de todos no diagnóstico precoce, na prevenção e na resolução deste problema nacional e mundial. As conclusões do estudo de Sá (2012) também vêm reforçar a necessidade de esclarecer e mobilizar toda a comunidade educativa e a comunidade envolvente, na prevenção e no combate à violência e ao bullying, nomeadamente através da adoção de políticas globais e sistemáticas de escola. 


\section{Referências}

ALLMEN, M. R.V. Des mots aux acts: terminologie et représentation des migrations, des repports sociaux e des relations interculturelles. In: LABAT, C.; VERMES, G. Culture ouverts, sociétés interculturelles: du contact à l'interacion. Paris: Éditions Fontenay; St-Cloud ; Éditions l'Harmattan, 1994. v. 2.

BEANE, A. A sala de aula sem bullying. Porto: Porto Editora, 2006. tora, 2011.

Proteja o seu filho do bullying. Porto: Porto Edi-

BLAYA, C. Violência e maus-tratos em meio escolar. Lisboa: Instituto Piaget, 2008. (Coleção Horizontes Pedagógicos, 145).

CARVALHOSA, S. F.; MOLEIRO, C.; SALES, C. A situação do bullying nas escolas portuguesas. Interacções, v. 5, n. 13, p. 125-146, 2009a. Disponível em: <http://www. eses.pt/interaccoes>. Acesso em: 04 abr. 2016.

. Violence in portuguese schools: national report. International Journal of Violence and School, n. 9, p. 57$78,2009 b$.

CHESNAIS, J.-C. Histoire de la violence. Paris: Laffont, 1981.

COSTA, E.; VALE, D. A violência nas escolas. Lisboa: Instituto de Inovação Educacional, 1998.

COSTA, R. J. Violência na escola: verdadeira ou falsa questão? A Página da Educação, Porto, n. 101, 2001. Disponível em: <http://www.apagina.pt/?aba=7\&cat $=101 \&$ doc $=8362 \&$ mid $=2>$. Acesso em: 04 abr. 2016.

COWIE, H. ; SMITH, P. K. La violence en milieu scolaire au Royaume Uni. In: DEBARBIEUX, E.; BLAYA, C. (Org.). Violence in schools: ten approaches in Europe. Paris: ESF, 2001.

DELORS, J. et al. Educação: um tesouro a descobrir. Porto: Editora ASA, 1996. Relatório para a UNESCO da Comunicação Internacional sobre a Educação para o século $\mathrm{XXI}$.

ESTRELA, T. ; MARMOZ, L. Indiscipline et violence à l'école: études européennes. Paris: L'Harmattan, 2006.

FANTE, C. A. Z. Estudos realizados em uma escola da rede pública em São José do Rio Preto. Brasil, 2002.

FERREIRA, A.; PEREIRA, B. Os materiais lúdicos nos recreios e a prevenção do bullying na escola. In: PEREIRA, B.; PINTO A. (Org.). A escola e a criança em risco: intervir para prevenir. Porto: Edições ASA, 2001. p. 235247.
FERREIRA, E. D. Gestão de conflitos e prevenção da violência em meio escolar: das percepções dos diferentes "actores" às práticas mais correntes em duas escolas do $2^{\circ}$ ciclo do ensino básico da região centro: enquadramento teórico: estudos de caso. 2008. $681 \mathrm{f}$. Tese (Doutoramento em Ciências da Educação) - Universidade Aberta, Lisboa, 2008.

FORMOSINHO, M. D.; SIMÕES, M. C. T. O bullying na escola: prevalência, contextos e efeitos. Revista Portuguesa de Pedagogia, ano 35, n. 2, p. 65-82, 2001.

GONZÁLEZ, J. A. T. Educação e diversidade: bases didáticas e organizativas. Porto Alegre: ARTMED Editora, 2002.

HAYDEN, C.; BLAYA, C. Violent and aggressive behaviour in English schools. In: DEBARBIEUX, E.; BLAYA, C. Violence in schools: ten approaches in europe. Paris: Elsevier, 2001.

JUNGER-TAS, J.; MARSHALL, I. H.; RIBEAUD, D. Delinquency in an international perspective: the international self-reported delinquency study (ISRD). The Hague: Kugler Publications, 2003.

LOPES NETO, A. A.; MONTEIRO FILHO, L.; SAAVEDRA, L. H. Programa de redução do comportamento agressivo entre estudantes. Rio de Janeiro: ABRAPIA, 2003.

LOPES NETO, A. A.; SAAVEDRA, L. H. Diga não para o bullying! Rio de Janeiro: ABRAPIA, 2003.

MARTÍNEZ, J. M. A. La intimidácion y el maltrato en los centros escolares (bullying). Revista Lan Osasuna, n. 2, p. 1-13, 2002.

MELLOR, A. Bullying in scottish secondary schools. Edinburgh: Scottish Council for Research in Education, 1997.

MULLER, J. Princípio da não violência. Lisboa: Instituto Piaget, 1995.

NOGUEIRA, R. M. C. P. A. A prática de violência entre pares: o bullying nas escolas. Revista Iberoamericana de Educação, Madrid, n. 37, p. 93-102, 2005.

. Violências nas escolas e juventude: um estudo sobre o bullying escolar. 2007. Tese (Doutoramento em Educação) - Pontifícia Universidade Católica de São Paulo, São Paulo, 2007.

OLWEUS, D. Agression in the school: bullies and whipping boys. Washington DC: Hemisphere, 1978.

. Bullying at school: what we know and what we can do. Oxford: Blackwell, 1993.

Bullying at school: what we know and what we can do. Oxford: Blackwell Publishing, 2005. 
Conductas de acoso y amenaza entre escolares. Madrid: Morata, 1998.

Violences entre élèves, harcélements et brutalités. Paris: ESF, 1999.

PAIAS, T.; ALMEIDA, A. Esteja atento ao bullying escolar. Psicronos, 2006. Disponível em: <http://www.psicronos.pt/ artigos/bullyingescolar.html>. Acesso em: 26 mar. 2016.

PEDRO, A. et al. Bullying e violência na e da escola: propostas de intervenção para professores. Aveiro: Universidade de Aveiro, 2012.

PEREIRA, B. et al. Bullying in portuguese schools. School Psychology International, v. 25, n. 2, p. 241-254, 2004.

PEREIRA, B. O. Para uma escola sem violência: estudo e prevenção das práticas agressivas entre crianças. Coimbra: Fundação Calouste Gulbenkian; Fundação para a Ciência e a Tecnologia, 2008.

PERES, A. Educação intercultural: utopia ou realidade? Porto: Profedições, 2000.

PESCADOR, J. E. P.; DOMíNUEZ, M. R. F. La violencia escolar: un punto de vista global. Revista Interuniversitaria de Formación de Profesorado, Zaragoza, España, n. 41, p. 19-38, ago. 2001.

RAMIREZ, F. Condutas agressivas na idade escolar. Amadora: McGraw-Hill, 2001.

RAMOS, N. Acolher e trabalhar com jovens entre culturas: contextos e competências interculturais. In: MEDEIROS, T. (Org.). Adolescência: desafios e riscos. Ponta Delgada: E. Letras Lavadas, 2013a. p. 107-135.

Crianças e famílias em contexto migratório e intercultural: desafios às práticas e políticas educacionais, sociais e de cidadania. In: RAMOS, N. (Coord.). Educação, interculturalidade e cidadania. Bucareste: Ed. Milena Press, 2008. p. 53-72.

Educar para a interculturalidade e cidadania: princípios e desafios. In: ALCOFORADO, L. et al. Educação e formação de adultos: políticas, práticas e investigação. Coimbra: Ed. Universidade de Coimbra, 2011. p. 189-200.

. Interculturalidade, educação e desenvolvimento: o caso das crianças migrantes. In: BIZARRO, R. (Org.). Eu e o outro: estudos multidisciplinares sobre identidade(s), diversidade(s) e práticas interculturais. Porto: Areal Editores, 2007a. p. 367-375.

Interculturalidade(s) e mobilidade(s) no espaço europeu: viver e comunicar entre culturas. In: PINA, H.; MARTINS, F.; FERREIRA, C. (Ed.). The overarching issues of the european space. Porto: Faculdade Letras da Universidade do Porto, 2013b. p. 343-360.
Psicologia clínica e da saúde. Lisboa: Universidade Aberta, 2004.

Sociedades multiculturais, interculturalidade e educação: desafios pedagógicos, comunicacionais e políticos. Revista Portuguesa de Pedagogia, Lisboa, ano 41, n. 3, p. 223-244, 2007b.

ROCHÉ, S. En quête de sécurité: causes de la délinquence et nouvelles réponses. Paris: Armand Collin, 2003. (Coleção Sociétales).

SÁ, J. I. A. de. Bullying nas escolas: prevenção e intervenção. 2012. Tese (Doutoramento em Ciências da Educação) - Universidade de Aveiro, Aveiro, 2012.

SANTOS, A. K. C. da C. Crianças sobredotadas: dinâmicas familiares, escolares e socioculturais. 2012. $413 \mathrm{f}$. Tese (Doutoramento em Ciências da Educação) - Universidade Aberta, Lisboa, 2012.

SINGER, M. I. et al. Adolescents exposure to violence and associated symptoms of psychological trauma. The Journal of the American Medical Association, v. 273, n. 6 , p. 477-482, 1995.

SMITH, P. K. et al. Profiles of non-victims, escaped victims, continuing victims and new victims of school bulling. British Journal of Educational Psychology, v. 74, n. 4, p. 565-581, 2004

SMITH, P. K. The nature of school bullying: a cross-national perspective. Londres: Routledge, 1999.

SMITH, P. K.; PEPLER, D.; RIGBY, K. Bullying in schools: how successful can interventions be? London: Cambridge University Press, 2004.

SMITH, P. K.; SHARP, S. School bullying: insights and perspectives. London: Routledge, 1994.

THOMPSON, D.; ARORA, T.; SHARP, S. Bullying effective strategies for long-term improvement. Londres: Routledge Falmer, 2003.

UNICEF. Hidden in plain sight: a statistical analysis of violence against children. New York: UNICEF, 2014.

VEIGA, F. H. Indisciplina e violência na escola: práticas comunicacionais para professores e pais. Coimbra: Almedina, 2001.

YOON, J. S.; KERBER, K. Bullying: elementary teacher's attitudes and intervention strategies. Research in Education - An Interdisciplinary International Research Journal, v. 69 , n. 1, p. 27-35, 2003. 